\title{
FENOMENA BUTCHI DAN DAMPAK SOSIALNYA : STUDI KASUS PADA MASYARAKAT DI KECAMATAN KOTO TANGAH KOTA PADANG
}

\author{
Gustiva Yelviani, Fatmariza, Susi Fitria Dewi \\ Program Studi Pendidikan Pancasila dan Kewarganegaraan \\ Universitas Negeri Padang \\ Yelvini.gustiva@gmail.com
}

\begin{abstract}
Lesbian phenomena are increasingly prevalent over time, this is evidenced by the complete newspaper completed. which addresses these issues in some time which are discussed continuously. This article tries to explain the butchi phenomenon and its thinking on the lives of the people of Koto Tangah subdistrict, Padang City. This study uses qualitative information with 7 deliberately chosen people. The research data was collected by observation, interviews and data analysis studies using qualitative data management steps. The results showed that there were 5 causative factors that influenced genetic factors, broken heart factors, family considerations or damage, environmental influences, and the influence of social media. While the social phenomenon of Butchi was announced as being ostracized and insulted. In addition, the community also needs to be bothered because it no longer applies the values of norms and religion. The difficulty of the butchi phenomenon will affect the next generation. Responding to the matter in question is the efforts made by the government that involve the community are raiding, netting, searching and fostering. It is undeniable that the impact of Butchi's social phenomena is very bad for opposition, families too.
\end{abstract}

Keywords: Lesbian, Social Impact, Butchi Phenomenon

\section{Abstrak}

Fenomena lesbian kian marak seiring waktu, hal ini dibuktikan dengan dengan surat kabar secara waktu yang berdekatan. yang membahas masalah-masalah tersebutdalam beberapa waktu yang berdekatan secara terus menerus. Artikel ini bertujuan untuk menjelaskan fenomena butchi dan dampaknya terhadap kehidupan masyarakat kecamatan Koto Tangah Kota Padang. Penelitian ini menggunakan pendekatan kualitatif dengan informan 7 orang butchi yang dipilih secara purposive. Data penelitian dikumpulkan dengan observasi, wawancara dan studi analisis data menggunkan langkah-langkah pengelolahan data kualitatif. Hasil penelitian menunjukkan bahwa ada 5 faktor penyebab diantaranya faktor genetik, faktor patah hati, kurangnya perhatian keluarga atau broken home, pengaruh lingkungan, dan pengaruh media 
13 |Fenomena Butchi dan...

sosial.Sedangkan dampak sosial fenomena butchi diantaranya seperti dikucilkan dan dihina. Selain itu masyarakat juga merasa terganggu karena didaerahnya tidak lagi menjalankan nilai aturan norma dan agama.Adanya ketakutan fenomena butchi akan mempengaruhi generasi penerus.Menyikapi hal tersebut upaya yang telah dilakukan pemerintah beserta masyarakat adalah merazia, menjaring, menangkap dan membina. Dapat disimpulkan bahwasanya dampak sosial fenomena butchi sangat buruk terhadap pelaku, keluarga maupun masayrakat.

\section{Kata kunci: Lesbian,Dampak Sosial, Fenomena Butchi}

\section{Pendahuluan}

Seiring berjalannya watu ada suatu fenomena yang timbul didalam kehidupan masyarakat, yaitu fenomena lesbian. Dimana dengan adanya perkembangan zaman dan teknologi membawa pengaruh dan perubahan yang dapat mempengaruhi kehidupan masyaraka. Fenomena lesbian ini sangat mempengaruhi masyarakat yang banyak sekali menimbulkan pro dan kontra. Diamana masyarakat Indonesia terkususnya Sumatera Barat yang sangat kuat dan kental Agamanya.Seperti falsafahnya "adat basandi syarak, syarak basandi kitabllah" yang berartikan adat bersandikan kepada ajaran agama dan kitab suci Al-Qur'an.

Hal serupa juga diutarakan oleh beberapa penelitian terdahulu dari( Rizqi Mahmuda, 2016) menyatakan fenomena lesbian merupakan hal yang bertentangandengannorma-norma yang berlaku di Sumbar. Hal serupa dinyatakan (Shella, dkk 2016) menyatakan lesbian diangap kaum marginal di dalam lingkunga nmasyarakat indonesia yang melarang keras, mengucilkan dan menghukum para LGBT. Selanjutnya (Devi Citra Yanti, 2016) menyatakan LGBT di Indonesia mengalami penolakan dan penerimaan. Sedangkan (Shendy Tamara, 2016) menyatakan komunikasi merupakan hal yang paling penting dalam menjalin suatu relasi dan interaksi terhadap orang lain. Serta (Fitri Wayuni, 2016) menyatakan bahwa islam telah mengatur segala sendi kehidupan yang salah satunya fitrah manusia.

Adapun perbedaan antara penelitian ini dengan penelitian terdahalu yakninya didalam penelitian penulis hanya mengememukakan dampak sosial dari fenomena butchi terhadap sipelaku, keluarga beserta masyarakat. Sedangkan penelitian terdahulu lebih mengemukakan identitas diri dan orientasi lesbian, peran kerja sosial, self disclosure lesbian, sanksi pelaku LGBT serta komunikasi persuasive wanita belok. Keterbatasan penulisan ini yakninya penliti tidak membahas segala aspek yang terjadi pada lesbian. 
Berdasarkan pemberitaan baru-baru ini Sumatera Barat menjadi bahan perbincangan dimana LGBT terbesar terdapat di provinsi Sumatera Barat. Terbukti dengan laporan yang ditemui beberapa surat kabar dalam jangka waktu yang pendek. Angka LGBT Indonesia kian meningkat setiap tahun, di sisi lain perhimpunan konselor VCT HIV indonesia (PKVHI) menyatakan LGBT disumbar mencapai 25.000 lebih. Jumlahrincian 14.469 orang LSL (lakisamalaki) ditambah 2.501 waria, dan 9.024 orang pelanggan waria, dan diperkirakan sisanya 946 lesbian. Penelitian dilakukan bekerja sama dengan Badan Penelitian dan Pengembangan Provinsi Sumbar. (sumber: hariansinggalang, 24 april 2018) sedangkan data lesbian yang diterbitkan Satpol PP kota Padang sebanyak 16 orang lesbian yang berhasil mereka amankan pada tahun 2018 .

Lesbian terbagi dua golongan mulai dari butchi yang berwatak dan berpenampilan seperti laki-laki, dan femmi yang berpenampilan layak nya wanita tulen dan penyuka sesama jenis. Seperti yang dinyatakan ada dua lesbian yang sering kali dibedakan Jones dan Hesnard (dalam Beauvoir,2003), yaitu perempuan lesbian yaitu perempuan maskulin yang berhasratmeniru laki-laki, yang biasa disebut Butch dan seorang feminim yang taut terhadap laki-laki yang biasa disebut femme.

Keterbatasan solusi yang pernah ada yaitu tidak kebanyakan orang atau peneliti yang memberikan solusi bahwasanya perlu diadakan pendekatan anak dengan orang tua, perlunya dukungan orang tua terhdap pertumbuhan dan perkembangan seorang anak. Serta seringkali orang tidak mengaitkan masalah apapun dengan agama. Padahal agama adalah sesuatu yang harus depedomani dan kita sebagai manusia harus berpegang teguh terhadap ajaran agama dan meyakini apa yang diajarkan oleh agama dan keyakinan yang kita yakini. Serta per;unya da tindakan dan undang-undang kusus mengenai larangan lesbian atau LGBT di Inodenisa terutama Sumatera Barat.

Kelebihan solusi yang ditawarkan dalam artikel penelitian ini, ialah peneliti melibatkan semua pihak untuk ikut serta memberikan upaya terhdap permasalahan enomena butchi tersebut. Yakninya para tokoh agam serta adat juga ikut serta dalam memberikan solusi dan ikut serta berupaya untuk mengurangi fenomena yang sangat tidak layak seperti ini.

Adapun tujuan penulisan artikel ini untuk mendeskripsikan faktor-faktor penyebab maraknya fenomena butchi di Kota Padang. Mendiskripspikan dampak fenomena butchi terhadap keluarga pelaku dan masyarakat di Kota Padang. Dan Mendiskripspikan upaya yang telah dilakukan oleh pemerintah beserta masyarakat untuk mengurangi angka lesbian di Kota Padang. Serta bertujuan untuk mengimplementasikan ilmu-ilmu yang didapatkan saat perkuliahan Pengantar Sosiologi. Sebagai 
masukan kepada kelompok LGBT dalam memahami makna sayang yang sesungguhnya, serta untuk mengatasi fenomena lesbian sebagai masukan kepada pemerintah dalam membuat suatu kebijakan terhadap kelompok LGBT.

\section{A. Metodologi Penelitian}

Penelitian ini adalah penelitian kualitatif yang bertujuan untuk mendiskripsikan tentang faktor-faktor penyebab maraknya fenomena butchi dan dampak fenomena butchi terhadap pelaku, keluarga dan masyarakat, serta upaya yang telah dilakukan pemerintah beserta masyarakat untuk mengurangi angka lesbian di Kota Padang. Informan penelitian ditentukan secara purposive sampling, berjumlah 20 orang dan diantaranya 7 orang butchi. Jenis data yang digunakan dalam penelitian ini adalah data primer dan data sekunder. Pengumpulan data dilakukan dengan wawancara tidak terstruktur, observasi dan studi dokumentasi. Uji keabsahan data dengan menggunakan teknik trianggulasi data. Teknik analisis data dilakukan dengan tahapan pengumpulan data, reduksi data, penyajian data dan mengambil kesimpulan atau verifikasi data. Waktu observasi dan penelitian kurang lebih 2 bulan.

\section{B. Hasil dan Pembahasan}

\section{Faktor penyebab maraknyaFenomenaButchi di Kota Padang}

Adapun darifenomena butchi tersebut dapat ditemui beberapa Faktor-faktor penyebab maraknyaFenomenaButchi di Kota Padang yaitu sebagai berikut:

\section{a. Faktor genetik}

Salah satu faktor yang mempengaruhi butchi untuk berprilaku menyimpang disebabkan oleh faktor genetik yang dimana mempengaruhi biologis seorang anak, rasa minat yang tinggi untuk menjadi sosok laki-laki dibandingkan dengan menjadi sosok perempuan. Tomboy dari kecil akan mempengerahui seseorang untuk tetap terus melakoni apa yang ia sukai dan terbawa-bawa hingga ia besar. Seperti bebarapa kasus yang peneliti temui. Hal ini diperkuat oleh temuan penelitian terlebih dahulu Menurut penelitian terdahulu oleh (Astriy Budiarty, 2011) menyatakan faktor penyebab butchi diantaranya pengalaman seksual buruk pada masa kanak-kanak. Teori yang berkaitan dengan ini ialah teori perilaku menyimpang yang dimana Faktor penyebab yang dari perilaku menyimpang adalah faktor biologis. Yaitu terbagi dari hereditas yang dimana hasil-hasil penelitian megungkapkan bahwa karakteristik anak dapat dipengaruhi oleh faktor genetik yang bersifat bawaan dari orangtua. 


\section{b. Rasa kekecewaan yang mendalam terhadap laki-laki \\ Rasa}

kekecewaandarilawanjenismenyebabkanmerekaberprilakumenyimp ang. Menurut penelitian terdahulu oleh (Astriy Budiarty, 2011) menyatakan faktor penyebab butchi diantaranya pengalaman seksual buruk pada masa kanak-kanak. Ada yang mengatakan bahwa pelecehan seksual dan kekerasan yang dialami seorang prempuan pada masa kanak-kanak dapat menyebabkan anak tersebut menjadi seorang lesbian pada waktu dewasanya. Teori yang berkaitan yaitu teori perilaku menyimpang yang dimana faktor Kegagalan terhadap suatu yang diinginkan atau tidak tercapainya segala bentuk sosialisasi yang sering dialami oleh para remaja seperti putus cinta menjadikan pelaku merasa terbebani, merasa tidak ada lagi tujuan hidup, hingga hilangnya rasa ketidak sadaran pada dirinya.

\section{c. Kurangnya perhatian keluarga dan keluarga broken home}

kurangnya perhatian keluarga dan keluarga yang hancur (broken home) dapat menyebabkan anak memiliki perilaku yang buruk dimasa yang akan datang. Hal ini yang menyebabkan anak senantiasa mencari kesenangan diluar rumah dan berprilaku menyimpang untuk menarik perhatian seseorang. Hal ini diperkuat oleh (Astriy Budiarty, 2011) yang merupakan faktor penyebab butchi adalah pengaruh keluarga dan kondisi hubungan orang tua. Hubungn anatara orang tua yang sering cekcok. Anatar orang tua dan dengan anak-anak yang tidak harmoni atau bermasalah juga dapat mempengaruhi. Teori yang berakaitan dengan ini ialah teori perilaku menyimpang yang diamanafaktor penyebab seseorang untuk berprilaku menyimpang ada psikososial. Diperkuat oleh teori psikososial Kurangnya perhatian dari sebuah keluarga dan Ketidak harmonisan dalam rumah tangga.

\section{d. Pengaruh Lingkungan}

Pengaruh lingkungan juga sangat berperan dan mempengaruhi kehidupan seseong. Sebab seseorang yang hidup didalam lingkungan yang baik-baik akan senantiasa menjadi pribadi yang baik. Begitu juga sebaliknya, seseorang yang hidup didalam lingkungan yang buruk senantiasa mencontoh dan berprilaku yang buruk juga. Seperti penelitian terdahulu oleh (Astriy Budiarty, 2011) yang menyatakan salah satu faktor penyebab lesbian atau butchi oleh pengaruh lingkungan. Pengaruh lingkungan yang buruk dapat mempengaruhi seseorang untuk bertingkah laku seperti orangorang dimana dia berada.Teori yang berk aitan dengan hal ini ialah teori perilaku menyimpang yang diamna terdapat bebarapa teori seperti teori (differential association) Teori ini dikemukakan oleh 
Edwin H. Sutherland. Menurut teori ini penyimpangan bersumber dari pergaulan dengan sekelompok orang yang telah menyimpang. e. Pengaruh Media Sosial.

Faktor terakhir yang dapat peneliti temui adalah pengaruh media sosial yang dapat mempengaruhi anak hingga menjadi butchi. Media sosial pada dasarnya memang memepermudah kita untuk mengaskese dan mencari indfomasi apapun. Berikut berdasarkan penelitian terdahulu oleh (Astriy Budiarty, 2011) yang sedikit berbeda menyatakan bahwasanya faktor penyebab butchi atau lebian disebabkan oleh pengalaman seksual buruk pada masa anakanak dan pengaruh lingkungan. Sebagian besar berdampingan dengan pengaruh media sosial yang dapat saya temui. Dimana karakter seseorang dapat dikenali dari faktor teman-temannya seperti dalam media sosial yang mereka akseses. Adapun teori yang berhubungan yaitu teori perilaku menyimpang yang diamana salah satu faktor yang menyebabkan seseorang untuk berprilaku menyimpang adalah Pengaruh lingkungan atau media massa yang dimana media sosial merupakan alat promosi yang efektif bisa berupa konten positif dan negatif.

2. Dampak social fenomena Butchi terhadap pelaku, keluarga dan masyarakat.

Adapun dampak yang ditimbulkan terhadap pelaku, keluarga dan masayarakat.

\section{a. Dampak terhadap Pelaku}

Dampak yang ditimbulkan dari fenomena butchi tersebut terhadap diri pelaku seperti pelaku kian dihina dan dijauhi oleh masyarakat. Butchi mengetahui apa yang mereka lakukan adalah sebuah kesalahan. Namun mereka hanya menajalani apa yang mereka suka. Mereka tidak bermaksud merugikan siapapun. Mereka berkomentar hanya ingin melakukan apa yang mereka senangi dan minati untuk kepentingan mereka pribadi.Namun mereka seringkali mendapatkan dampak yang tidak menyenangkan terhadap diri mereka.Adapun menurut penelitian terdahulu oleh (Devi citra yanti, 2016) menyatakan ditengah masyarakat yang memiliki prespsi kuat mengenai larangan terhadap seks bebas menyebabkan lesbian merasa terasing dan tida bisa memenuhi kebutuhan mereka untuk berekspresi. Adapun teori yang berkaitan dengan ini ialah teoori perilaku menyimpang yang diamana dampak perilaku menyimpang terhadap pelaku adalah: 
a.) Memberikan pengaruh psikologis atau penderitaan kejiwaan serta tekanan mental terhadap pelaku karena akan dikucilkan dari kehidupan masyarakat atau dijauhi dari pergaulan.

b.) Dapat menghancurkan masa depan pelaku penyimpangan.

c.) Dapat menjauhkan pelaku dari Tuhan dan dekat dengan perbuatan dosa.

d.) Perbuatan yang dilakukan dapat mencelakakan dirinya sendiri.

\section{b. Dampak terhadap Keluarga}

Selain menimbulkan dampak terhadap pelaku fenomena butchi juga menimbulkan dampak terhadap keluarga. Diantaranya mereka selalu mendapat cemooh dari tetangg amaupun dari masyarak tsekitar. Padahal mereka tidak selalu salah dalamha litu. Mereka hanya beharap masyarakat mampu berkerjasama dalam hal membimbing dan mengingatkan kepada keluarga maupun anak perempuannya agar senantiasa kembali kejalan yang benar dan kembali kekodrat yang semana mestinya mereka jalani.Adapun hal yang serupa menurut penelitian terdahulu oleh (Dewi Nurmal, dkk, 2006) menyatakan bahwasanya ditengah semarakanya lesbian di Indonesiat menimbulkan pro dan kontra dari masayarakat. Menimbulkan dampak negatif. Sebab lesbian sendiri masih merupakan merupakan fenomena yang menimbulkan kontroversi.Adapun teori yang berkaitan dengan hal ini ialah teori perilaku menyimpang yang dimana dampak dari terori perilau menyimpang adalah merugikan orang lain serta membawa dampak buuruk terhadap orang lain.

\section{c. Dampak terhadap masyarakat}

Adapun dampak sosial fenomena butchi tehadap masyarakat ialah masyarakat merasa terganggu, masyarakat merasa telah keluar dari aturan nilai, norma dan agama.Masyarakat takut akan mempengaruhi generasi penerus bangsa dimasa yang akan datang. Hal ini diperkuat oleh penelitian terdahulu oleh (Dewi Nurmal, dkk, 2006) yang beranggapan sama bahwasanya lesbian telah keluar dari ajaran agama yang berlaku di Indonesia. Keberadaan perempuan lesbian mendapatkan diskriminasi dari masyarakat yang menolaknya, dan akan semakin bertamabahnya konflik-konflik yang muncul dimasyarakat.Adapun teori yang berkaitan dengan hal ini adalah teori perilaku menyimpang yang dimana dampak dari teori perilaku menyimpang adalah 


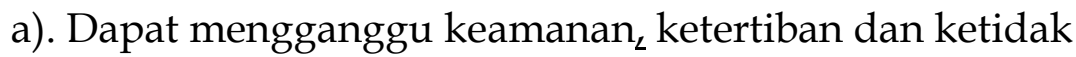
harmonisan dalam masyarakat.

b). Merusak tatanan nilai, norma, dan berbagai pranata sosial yang berlaku di masyarakat.

c). Menimbulkan beban sosial, psikologis, dan ekonomi bagi keluarga pelaku.

d). Merusak unsur-unsur budaya dan unsur-unsur lain yang mengatur perilaku individu dalam kehidupan masyarakat.

3. Upaya yang telah dilakukan pemerintah beserta masyarakat untuk mengurangi angka lesbian.

a. upaya pemerintah.

Adapun upaya yang telah dilakukan pemerintah untuk mengurangi angka lesbian yaitu dengan melakukan kebijakan sesuai perda 11 tahun 2005 mengenai pemberantasan penyakit masyarakat.adalah merazia, menjaring, menangkap dan membina.Adapun hal yang serupa dikemukakan oleh (Dewi Nurmal, dkk, 2006) di Indonesia tidak ada pelegalan yang mengijinkan perempuan menikah dengan perempuan. Karena masa depan perempuan ialah dengan menikah bersama lakilaki.Adapun teori yang digunakan ialah teori perilaku menyimpang yang terdiri dari teori Teori Fungsionalisme struktural berusaha melihat keberfungsian masing-masing elemen-elemen di dalam masyarakat secara keseluruhan bisa berjalan secara normal. Teori ini dikemukakan oleh Emil Durkheim yang menyatakan pemyimpangan merupakan bagian integral masyarakat dan memilik empat fungsi utama

b. Upaya masayarakat

Dengan melalukan kebiasaan tersebut dapat meningkatkan kehidupan yang lebih baik terhadap pelaku, keluarga, masyarakat dan pemerintah. Dengan melakuka nupaya menceramahi, mengingati dan melaporkan kepihak berwajib dapat mengurangi angka lesbian yang semakin melonjak tiapta hunnya. Dapat mencegah perlaku menyimpang dengan adanya control social dan edukasi pengajaran kepada generasi penerus bangsa dimasa sekarangdandimasa yang akan datang. Adapun hal yang serupa dikemukakan oleh (Devi Citra Yanti, 2016) menyatakan bahwasanya penyusunan orientasi masa depan sangat diperlukan guna menghindri kejadian yang buruk dimasa yang akan datang. Selanjutnya teori yang sama teori perilaku menyimpang dengan pembagian menggunakan teori anomie perilaku menyimpang merupakan pencerminan tidak adanya kaitan antara aspirasi yang ditetapkan kebudayaan dan cara yang dibenarkan oleh struktur sosial untuk mencapai tujuan tersebut. 


\section{Penutup}

Berdasarkan temuan penelitian dan pembahasan yang telah dilakukan dapat disimpulkan bahwasanya faktor penyebab maraknya fenomena butchi diantaranya lebih kepada pengaruh keluarga. Kurangnya perhatian keluarga dapat menyebabkan anak dengan senantiasa mencari kesenangan dan mencari perhatian diluar. Oleh sebab itu kurangnya perhatian keluarga dan keluarga dan keluarga yang hancur dapat menyebabkan anak berprilaku menyimpang. Serta dampak yang ditimbulkan dari fenomena butchi ini sangatalah bnyak terutama terhdap pelaku dan keluarga yang diperlakukan tidak adil didalam kehidupan masyrakat, serta dampak yang ditimbulkan terhdap masayarakat adanya keresahan dan kekhawatiran terhadap fenomena yang tidak layak ada sepert ini.

Peneliti telah menekuni bidang ilmu yang sesuai dengan penelitian ini diantaranya bidang ilmu Pengantar Soiologi yang dimana bidang ilmu ini membahas secara keseluruhan seluruhan seluk beluk kehidupan masyarakat. Serta menangani mengenai fenomena-fenomena yang ada didalam kehidupan masyarakat.

Implikasi penulisan artikel ini terhadap penelitian berikutnya ialah dapat membantu penelitian berikutnya memahami apa yang sebenarnya terjadi terhadap pelaku butchi. Serta penelitian berikutnya juga lebih muda memahami apa saja dampak yang ditimbulkan akibat fenomena ini. Serta tak lupa juga upaya yang telah dilakukan untuk menangani fenomena ini.

Adapun berdasarkan kepada kesimpulan-kesimpulan yang diambil berkaitan dengan penelitian ini, maka penulis menyampaikan saran yang kiranya dapat dilakukan dan bermanfaat bagi orang lain, diantaranya bagi:

1. Bagi Orang Tua

a. Menanamkan nilai-nilai positif bagi anaknya dan memperhatikan setiap perkembangan anaknya.

b. Memperhatikan pergaulan anaknya dengan teman-temannya.

c. Berikan arahan dan pecerahan tentang agama kepada anaknya agar dapat membedakan mana yang boleh dilakukan dan mana yang tidak boleh dilakukan.

d. Sebaiknya orang tua memberikan tambahan pendidikan dengan menyekolahkan anaknya di madrasah agar dapat tambahan ilmu agama.

2. Bagi Institusi yang Terkait (Sekolah, Dinas Sosial)

a. Memberikan penyuluhan-penyuluhan kepada anak-anak tentang dampak dari perilaku menyimpang/ LGBT / Lesbian (butchi) . 
21 |Fenomena Butchi dan...

b. Bagi pihak sekolah, agar memberikan arahan-arahan yang positif untuk menghindari perilaku menyimpang/ LGBT / Lesbian (butchi) .

c. Membina anak untuk mengikuti kegiatan ekstrakulikuler disekolah agar memiliki kegiatan yang bermanfaat untuk melatih, mendidik serta memberikan wawasan yang lebih bermanfaat bagi mereka.

d. Bagi dinas sosial agar memberikan sanksi agar remaja/ perempuan yang melakukan perilaku menyimpngatau lesbian (butchi).

3. Bagi Masyarakat

a. Kepada tokoh masyarakat, agar berperan dalam memberikan penyuluhan, penjelasan kepada warganya tentang bahaya dari perilaku menyimpang/ LGBT / Lesbian (butchi).

b. Memberikan sanksi kepada remaja yang melakukan perilakumenyimpang/ LGBT/Lesbian (butchi) agar mereka tidak mengulanginya lagi.

4. Bagi Butchi

a. Bagi butchi agar dapat menyadari bahwasanya butchiatauperilakumenyimpang dapat menimbulakan dampak negative dikemudian hari, makberhenti melakukan perilaku tersebutdankembalikejalan yang benar.

b. Remaja harus berinteraksi dan mencari kawan yang dapat membewa perubahan kearah yang positif dan tidak kearah yang menyimpang.

c. Agar lebih mendekatkan diri kepada Tuhan Yang Maha Esa dan mengerjakan hal-hal positif.

\section{DaftarPustaka}

\section{SumberBuku:}

Bungin, Burhan. 2007. Penelitiankualitatifkomunikasi,ekonomi, kebijakanpublic, danilmu social laiinya. Jakarta: KencanaPrenada Media Group.

Djamarah, Syaiful Bahri. 2014. Pola asuh orang tua dan komunikasi dalam keluarga (upaya membangun citra untuk membentuk pribadi anak). Jakarta: PT Rineka Cipta

Jhonson, Paul Doyle. 1994. Teori Sosiologi. jakarta: PT Gramedia Pustaka

Moleong, Lexi J. 2012. Metodologi Penelitian kulitatif. Bandung : Rosda Karya. 
Sugiyono,2014. Metodologi penelitian kualitatif dan REDD. Bandung: Alfabeta

SuhendiHendi\&WahyuRamdani, 2001. Pengantar stud iSosiologi Keluarga, Bandung: CV PustakaSetia.

Djamarah, Syaiful Bahri. 2014. Pola asuh orang tua dan komunikasi dalam keluarga (upaya membangun citra untuk membentuk pribadi anak). Jakarta: PT Rineka Cipta

\section{Sumber Jurnal:}

Abrar dan Tamrin. 2001. Kontruksi sesualitas: antara hak dan kekuasaan. Yogyakarta: pusat penelitian Universitas Gajah Mada

Adelina, Shella, Binaayati, \& Meilanny, Budiarty, S. 2016. Jurnal peran pekerja sosial dalam pembentukan konsep diri positif bagi lesbian kota Tasik, (vol 3 nomor 2) :155-291

Citra, Devi Y.2016. jurnal identitas diri dan orientasi masa depan kaum lesbian di samarinda. 4 (4) : 784-792

Tamara, Shendy. 2016. Jurnal self disclosure lesbian kepada aya dan ibumengenai orientasi seksualnya. vol 4 (1) : jurnal e-komunikasi

Wayuni, Fitri. 2018. Jurnal sanksi bagi pelaku LGBT dalam aspek hukum pidana islam dan kaitannya dengan hak asasi manusia. Vol IV nomor 2 :726-735

Sumber Skripsi:

Muhammad, Rizqi. 2016. "Kumunikasi persuasive wanita 'belok' (lesbian) dalam merubah orientasi seksual pasangan sejenis (studi deskriptif pada wanita di kota Padang)" Fisisp. Universitas Andalas. Sumatera Barat 